Vol. 2, n. 3 - Edição Especial: Ciclos Formativos em Ensino de Ciências.

\title{
A experiência formativa internacional no Projeto Paulo Freire de Mobilidade Acadêmica para Estudantes de Programas Universitários de Formação de Professores da Organização de Estados Ibero-americanos para a Educação, a Ciência e a Cultura (OEI)
}

\author{
International Formative Experience in the Paulo Freire Program for \\ Academic Mobility for Undergraduate Students from University \\ Programs of Teaching Training programs, from the Organization of \\ Iberoamerican States for Education, Science and Culture (OEI)
}

Leonardo Priamo Tonello (leonardo.priamo.tonello@gmail.com)

Universidade Federal da Fronteira Sul - UFFS

Resumo: Este trabalho se configura como um relato de experiência, no qual procuro desenvolver um processo reflexivo do meu percurso de participação da mobilidade internacional, no Projeto Paulo Freire de Mobilidade Acadêmica para Estudantes de Programas Universitários de Formação de Professores da Organização de Estados Iberoamericanos para a Educação, a Ciência e a Cultura (OEI), em colaboração com a Universidade Federal da Fronteira Sul (UFFS). Este possibilitou a oportunidade de fazer um intercâmbio na Universidade de Santiago de Chile (USACH), em Santiago, no Chile. Ao final do percurso, a mobilidade internacional, se mostrou uma potencializadora na formação de professores, na inserção dos profissionais em novos contextos, experimentando novos referenciais, contribuindo para a construção de uma identidade docente individual e compartilhada. $\mathrm{O}$ processo, se apresenta, pela troca de experiências e formação inicial de professores, ao encontro da qualidade do ensino e da valorização da valorização da profissão docente.

Palavras-chave: Mobilidade acadêmica internacional; Programa Paulo Freire; Intercâmbio.

Abstract: This paper constitutes as an experience report, which I aim to develop a reflexive process of my trajectory participating of an international mobility, in the Paulo Freire Program for Academic Mobility for Undergraduate Students from University Programs of Teaching Training programs, from the Organization of Ibero-American States for Education, Science and Culture (OEI), collaborating with the Universidade Federal da Fronteira Sul (UFFS). This program made it possible for me to take part in an exchange in the Universidad de Santiago de Chile (USACH), in Santiago, Chile. At the end of the trajectory, the international mobility demonstrated to be an enhancer in teacher's formation, in the placement of professionals in new contexts, trying new references and contributing to the construction of a new Teacher Identity, individual and 
Vol. 2, n. 3 - Edição Especial: Ciclos Formativos em Ensino de Ciências.

collective. The process presents itself in the exchange of experiences and teacher's initial training, in the meeting of teaching quality, and the valorization of the teacher's profession.

Keywords: international academic mobility; Paulo Freire Program; exchange

\title{
1. INTRODUÇÃO
}

\begin{abstract}
"Na condição de seres históricos, os homens, são seres que caminham para frente, que olham para frente; seres a quem o imobilismo a maçã de morte; para quem o olhar para trás não deve ser uma forma nostálgica de querer voltar, mas um modo de melhor querer conhecer o que está sendo, para melhor construir o futuro" (FREIRE, 1987, p. 103).
\end{abstract}

Início o trabalho, com este trecho de Paulo Freire, muito oportuno para a discussão que farei, sobre o projeto que leva o seu nome. O Projeto Paulo Freire de Mobilidade Acadêmica para Estudiantes de Programas Universitários de Formação de Professores é pertencente à Organização de Estados Ibero-americanos para a Educação, a Ciência e a Cultura (OEI). O projeto tem seu surgimento na "XXIV Conferência Ibero-americana de los Ministros da Educação", promovida pela OEI, na Cidade de México, em agosto de 2014. Este tem por objetivo, estabelecer a mobilidade acadêmica, para estudantes de graduação e pós-graduação em formação docente, entre instituições, por convênios e cooperação ibero-americana.

Sua proposta se fundamenta sobre pressupostos de que o elemento fundamental no processo de internacionalização da educação superior, assim como do conhecimento e tecnologia, ultrapassando fronteiras, experimentando culturas, se define principalmente pelo processo de mobilidade acadêmica internacional. Este constante intercâmbio de experiência entre estudantes, busca estabelecer uma ampla formação de licenciados de forma globalizada, contribuindo com a construção de futuros professores da Educação Básica, fortalecendo os espaços formativos de atuação destes profissionais, e também como forma, de superar as "barreiras" entre a comunidade ibero-americana. Acredita-se na formação do professor formador.

Nesse sentido, o projeto também objetiva por consequência a valorização destes profissionais da educação, seja de forma social ou intelectual, agregando na carreira 
Vol. 2, n. 3 - Edição Especial: Ciclos Formativos em Ensino de Ciências.

docente. Prioriza-se o ensino público, em suas mais variadas dimensões, principalmente em relação às universidades públicas, e seu compromisso com a educação escolar, em diversos níveis de formação. Com estes aspectos em seu princípio, o Projeto Paulo Freire, se reflete em projetos e experiência já existentes em matéria de Mobilidade Acadêmica Internacional, como o Programa de Intercâmbio e Mobilidade Acadêmica (Pima), o Programa Pablo Neruda e outras práticas de intercâmbio no âmbito dos países do Mercosul. Sendo assim, também amplia os horizontes como o próprio programa Erasmus (European Action Scheme for the Mobility of University Students), estabelecendo alianças entre Iberoamérica e a União Europeia.

Sendo assim, no contexto que foi exposto até o momento, este trabalho se configura como um relato de experiência, no qual procuro desenvolver um processo reflexivo do meu percurso de participação da mobilidade internacional, do Programa Paulo Freire, da OEI, em colaboração com a Universidade Federal da Fronteira Sul (UFFS). Que possibilitou a oportunidade de fazer um intercâmbio na Universidade de Santiago de Chile (USACH), em Santiago, no Chile. Como acadêmico do curso de Ciências Biológicas - Licenciatura, na UFFS - Campus Cerro Largo, realizei as disciplinas com o curso equivalente na USACH, de Pedagogia em Química e Biologia, pertencentes à Faculdade de Química e Biologia.

O Chile se demonstra como um fundamental país para desenvolver uma experiência de mobilidade acadêmica. Na América Latina, o Chile foi um dos grandes precursores das mudanças na educação, desde o período do regime militar, como a privatização e a descentralização da educação, alcançando hoje umas dos maiores desempenhos na educação em provas internacionais, por exemplo (MINEDUC, 2012). A compreensão de todo esse enredo permite compreender melhor os pontos positivos e negativos do sistema educacional, bem como o processo de ensino e aprendizagem, no qual se baseiam as atividades educativas e suas possibilidades. Também deve ser levado em conta que o conhecimento de outros povos e países, como a sua própria educação, é um tanto complexo e "[...] para fazer comparações, além da dificuldade de entender diferentes línguas e seus significados complexos, existe, o problema do conhecimento e 
Vol. 2, n. 3 - Edição Especial: Ciclos Formativos em Ensino de Ciências.

a interpretação de sua história e cultura" (FRANCO, 2000, p.288). Por, isso a necessidade de integrar estes conhecimentos dentro do processo investigativo, visto que pertence também na formação histórica do sistema de ensino e do processo educativo.

\section{DESCRIÇÃO DAS ATIVIDADES}

A universidade receptora desta mobilidade foi a Universidade de Santiago de Chile (USACH), localizada na capital Santiago do Chile. Por ser do curso de origem em Ciências Biológicas - Licenciatura, na UFFS - Campus Cerro Largo, realizei atividades e disciplinas que são equivalentes ao meu curso. $\mathrm{O}$ curso equivalente no USACH se denomina Pedagogia em Química e Biologia, pertencente à Faculdade de Química e Biologia.

Os Componentes Curriculares realizados foram: Didática Geral; Iniciação ao Ensino Escolar II; Metodologia de Pesquisa em Educação. Ressalto que foram fundamentais, com meus ideais de formação profissional na profissão docente como professor em formação inicial e futuro professor no Ensino de Ciências e Biologia. Na minha opinião, a aprendizagem e pesquisa não só ocorrem com base estritamente a um programa disciplinar, mas também uma imersão constante nos espaços da universidade de Santiago, como eventos e conferências acadêmicas, atividades culturais, a integração com a comunidade acadêmica, assim como outros intercambistas de todo o mundo apresentando um importante espaço multicultural e troca de experiências entre o processo de integração acadêmica e social.

A USACH apresenta uma caminhada estruturada de formação, com mais de 169 anos, sendo, segundo os rankings, uma das melhores universidades do Chile e também, bem posicionada em nível latino-americano e mundial (QS, 2019). Um ponto vantajoso da universidade, está no fato da mesma contar com um imenso campus universitário, isto permite uma melhor integração entre os estudantes de toda a universidade e de todas as áreas do conhecimento, já que seu campus, não é dividido e fragmentado, formando um verdadeiro ambiente de cidade universitária. 
Vol. 2, n. 3 - Edição Especial: Ciclos Formativos em Ensino de Ciências.

\section{DISCUSSÃO DO RELATO}

Pude ter contato com diferentes aspectos relacionados à Ciência e à Biologia, entendendo como ocorre o desenvolvimento científico, considerando que não é globalmente homogêneo, mas com particularidades e contextos, como a própria cultura científica.

Ao falar na cultura científica, de certa forma, como uma linguagem para entender a ciência e como ela é estabelecida. No ambiente escolar, por exemplo, deve-se desenvolver, para a construção de uma cultura científica, relacionada à participação da sociedade, configurando parte do processo de ciência e tecnologia, em sua evolução e transformação, como um mecanismo de controle coletivo. O Ensino de Ciências e Biologia, ao mesmo tempo em seu escopo, tem papel fundamental para essa abordagem social na ciência.

O Ensino, também se torna relevante, na perspectiva do senso crítico dos sujeitos, em um contexto atual, no qual é muito difícil gerenciar toda a informação disseminada, pelos mais diversos meios de popularização da ciência - principalmente na alta expansão de produção. Isso, por outro lado, acaba gerando certas deformações e manipulações na ciência e em suas idéias. As tecnologias da informação, por exemplo, contribuem para esse gigantesco fluxo de divulgação científica com a sociedade usuária de ambientes virtuais (ANTONELLI-PONTI et al., 2018). Cabe ao sujeito filtrá-los, mas ao mesmo tempo - recíproco - do sistema de ensino e aprendizagem, para que possam fazê-lo.

Pouco a sociedade intervém em processos de produção em larga escala, mas precisamos criar mecanismos para que os cidadãos desenvolvam um senso crítico de desenvolvimento científico-tecnológico, em um movimento conjunto da conhecida tríade Ciência, Tecnologia e Sociedade (CTS) ${ }^{1}$. A educação, por sua vez, desempenha um papel fundamental em todo esse processo.

A mobilidade internacional possibilitou contribuir com os meus estudos e formação, tendo em vista a complexidade do ser professor, aperfeiçoando o conhecimento de uma forma abrangente, aperfeiçoando a leitura de mundo e na constituição como professor em formação inicial e na futura atuação profissional. Os Componentes Curriculares que realizei me permitiram conhecer um pouco mais sobre o sistema de

${ }^{1}$ Campo do conhecimento que estuda as interrelações entre ciência-tecnologia-sociedade e suas múltiplas influências. 
Vol. 2, n. 3 - Edição Especial: Ciclos Formativos em Ensino de Ciências.

ensino do Chile, mais especificamente de algumas escolas de Santiago, nas quais, no Ensino de Ciências e Biologia, fiz observações e práticas orientadas. Isto tornou possível conhecer a organização e o sistema de educação, planejar atividades relacionadas com a realidade dos alunos, a aprendizagem da organização curricular dos aspectos levados em consideração no processo de ensino e aprendizagem, desenvolvendo um movimento de professor investigador assim, também por um processo de investigação-ação, transformando os espaços e caminhos formativos. Tudo isso leva em consideração a formação de cidadãos, que são ativos e capazes de tomar decisões em seus contextos, desenvolvendo e buscando sua autonomia pessoal e coletiva.

Em relação ao processo do professor-investigador, posso considerar, que foi fundamental, para compreender o contexto educativo e também do Ensino de Ciências e Biologia em geral. Considero, que no momento de realizar tal perspectiva, mais me constituía professor. Quanto mais tentava compreender os fenômenos complexos, no qual estava submetido, mais me sentia dentro do processo de ensinar, de aprender, de ensino, de investigar, de se colocar como professor formador, de se sentir no construtivo e desafiante caminho formativo: tomar consciência do papel e da identidade docente.

Nesse sentido, Porlán Ariza (1987) considera que além de facilitador e mediador das capacidades de aprendizagem dos alunos, o professor, também deve atuar como investigador dos processos na aula. Em outras palavras se pode dizer colocar o professor como investigador, seria centralizar também suas concepções de análise sobre sua ação docente e as questões que permeiam este processo formativo. No entanto, por vez, exige uma mobilização sistemática e reflexiva sobre o ser docente e sua atuação.

Percebo, que os elementos para o processo investigativo, dos professores no contexto escolar, não é algo que exige uma mobilização muito grande, visto que o professor está em constante contato com estes elementos em seu cotidiano, seja na escola como um todo, como sua sala de aula. No entanto, percebo, como corrobora Porlán Ariza (1987), que o movimento como professor-investigador é um trabalho que se dificulta na questão formativa, que forma a base e a motivação para esta realização.

Um exemplo bem claro desta necessidade de se pensar sobre o processo realizado e priorizado em sala de aula, são os resultados do estudo internacional TIMSS (2011) (Trends in International Mathematics and Science Study), que avalia o conhecimento de Matemática e Ciências, dos alunos do quarto e oitavo ano do Chile, apresentando, um 
Vol. 2, n. 3 - Edição Especial: Ciclos Formativos em Ensino de Ciências.

destaque em Latinoamérica - um dos níveis, mais baixos, entre os países pertencentes à OCDE (Organização para Cooperação e Desenvolvimento Econômico) - nos mostra, que os alunos tem um bom nível conceitual. No entanto, pode-se perceber, nestes mesmos dados, que os alunos não conseguem relacionar muito bem/aplicar em seus contextos estes conhecimentos, além de ter baixo raciocínio lógico. Investigar esse fenômeno, também é uma função do professor, pois ele pode alterar os rumos do ensino e da aprendizagem.

Considera-se ainda, que quando pensamos sobre a formação do sujeito, e nos diferentes temas sociocientíficos, ambientais e de saúde, por exemplo, é impossível não pensar na formação inicial e continuada de professores. A Mobilidade contribui nesse sentido, uma vez, que estabeleceu uma constante imersão na minha constituição profissional, considerando minha ação docente, como determinante na mediação do conhecimento e da formação escolar dos sujeitos envolvidos. Neste sentido, considero que os tempos contemporâneos de ensino, necessitam formar os alunos, não para receber um conteúdo acabado e universal, com um conhecimento distorcido da realidade, escondendo muitas vezes a própria Ciência e sua natureza - visão positivista, linear, que deve se reconfigurar para os aspectos da vida em sociedade e suas relações com a ciência, como um caminho convergente e multidimensional, apostando no ensino do pensamento crítico e reflexivo.

Meus estudos e constituição profissional levam em consideração o importante papel da Didática da Ciência, como tangencial e fundamental para a fundamentação teórico-prática-investigativa, no trabalho docente. Aqui, não considero a didática como sendo "boas" ações, que definem "bons" professores em sala de aula, mas sim, como uma Ciência desenvolvida sob diferentes modos, sendo fundamental para a construção de fins educativos (construção do conhecimento), configurando-se de forma geral, como uma ciência que ensina a ensinar, como colabora Izquierdo (2007). Ainda, neste sentido, posso considerar, que nos espaços formativos, muito tem-se a desenvolver a formação de professores, como seres pensantes, também dentro da Didática das Ciências, concordando com alguns pontos de Izquierdo (2007), destacando que: 
Vol. 2, n. 3 - Edição Especial: Ciclos Formativos em Ensino de Ciências.

I) Deve-se superar a ideia de que a didática, é apenas um adjetivo para integrar a práticas em sala de aula, ou até mesmo uma proposta pedagógica, no entanto, uma ciência, que integra uma grande diversidade de conhecimentos estruturados, para tratar dos problemas no processo de ensino e da aprendizagem;

II) Atualmente existe uma insistência de considerar apenas o teórico-prático, como conhecimento a ensinar, esquecendo o fundamental do processo: ensinar os alunos a pensar e situar-se na orientação de sua visão de mundo, e de suas concepções sobre ele; III) É recorrente a confusão entre conhecimento com disciplina, disciplina com programa, programa com livro didático. Deve-se ter claro que disciplina, tem caráter ambíguo, sendo que a didática, busca uma superação deste processo, e possíveis prováveis problemas deste, usando-se muitas vezes do livro didático e do programa curricular (norteador), tendo claro, que isso, deve ser flexível e não algo engessado (normativo) que define o fazer docente e caráter institucional. Em outras palavras, deve se ter consciência e autonomia, sobre o papel destes materiais, pois, temos diferentes contextos, com diferentes praticidades;

IV) Necessita-se formar e incorporar a Didática das Ciências na Escola Básica, assim como nos ambientes universitários, sendo um conhecimento fundamental na formação de professores e também da formação de sujeitos, dando visibilidade a esses profissionais e os conhecimentos trabalhados por estes. É necessário saber conteúdos - base teórica mas também, saber ensinar, avaliar o processo de ensino e aprendizagem e avaliar-se nele. Nesse sentido, se acredita que a perspectiva didática tem muito a contribuir com uma identidade docente, de valorização, e consolidação de um profissional formador.

Enfatizo, que o processo de ensino e aprendizagem, no que compreende o Ensino de Ciências e Biologia, apoiado pelo conhecimento da Didática da Ciências, assume fundamental importância de orientar as relações sociais, ou melhor dizendo, orientar o sujeito nela e no mundo, como pertencente a uma coletividade sistêmica e também autônoma - influente sobre seus fenômenos e organização, no que tange tomadas de decisões. O sujeito, é ativamente na sociedade, portanto, deve assumir sua participação como integrante da mudança social e cidadã (SANTOS, 2002). 
Vol. 2, n. 3 - Edição Especial: Ciclos Formativos em Ensino de Ciências.

A vivência de novas experiências proporcionadas, pelo programa Paulo Freire, se deram, não só no meio acadêmico, mas também no dia-a-dia como, conhecer a cultura, costumes e todo o enredo, nos coloca em um imenso laboratório de pesquisa, que é imersão social. A universidade estrangeira, apresenta alunos de vários países, o que contribui muito para a questão multicultural e também para a troca de conhecimentos. Acredito, que isso é um grande diferencial para uma maior abertura de mundo, apontando para a necessidade destes programas movimento de internacionalização, expandindo fronteiras, conhecimentos, culturas. Isso tudo, contribui para o grande conjunto da formação docente, sob diferentes perspectivas, motivações e acima de tudo, diferentes contextos. O Brasil tem muito a avançar nessa direção, desenvolvimento mecanismos para superar barreiras ainda existentes na cooperação acadêmica internacional, que estão muito além do físico e geográfico, mas também da troca de conhecimentos, culturas, ciência, tecnologia, e principalmente uma perspectiva da constituição docente, que contribua para uma identidade profissional, ao encontro do contexto ibero-americano.

\section{CONCLUSÃO}

Posso considerar que a mobilidade acadêmica internacional, contribuiu com o sentido complexo, em que muitas vezes nos perguntamos sobre a constituição docente, pois o professor, não nasce professor, com todas as características que se esperam para o trabalho em sala de aula, ele se se torna professor, em suas experiências e vivências constantemente. Este pensamento indagatório, é persistente e fugaz, principalmente em um professor em formação inicial.

A formação do professor formador é fundamental, para estabelecer, um processo, também de investigação sobre os processos de ensino, e não apenas mediador pedagógico. Assumir esse papel exige esforço formativo e motivacional, na perspectiva de melhorar as práticas e ações em sala de aula. Principalmente, no que compete o Ensino de Ciência e Biologia, nos tempos atuais, superarem e incorporarem os temas e desafios da sociedade da informação, da tecnologia, e da ciência. Conhecer quem é o aluno, dinamizar o processo de ensino e aprendizagem, também vem se mostrando fundamentais, assim como pensar a Didática da Ciência, como potencializadora e parte do processo, para 
Vol. 2, n. 3 - Edição Especial: Ciclos Formativos em Ensino de Ciências.

trabalhar os fenômenos e problemáticas no ensino, ou mais especificamente, no ensinar a ensinar.

Percebo cada vez mais, na medida que constituo-me professor, que sou um sujeito histórico-cultural (VIGOTSKI, 2001), em constante influência dos processos e das relações com o outro. Construo-me, e ao mesmo tempo, me reconstruo, como um conjunto de transformações que integram e fazem parte de minhas experiências formativas, que são intensificadas sobre o pluralismo contextual - como novos enredos internacionais.

Entre todos estes pressupostos, de atividades e intervenções, buscando em em sua maioria pautadas por um processo de investigação-formação-ação, como diferencial e categoria formativa, em que se aprende e ensina - e também se coloca em um espaçotempo de interação multicultural, acredito que foram determinantes para ir além, de um processo profissional e pessoal. A experiência de mobilidade agregará no que ainda está por vir, como um constante conjunto de relações e imersões no campo da docência. Nesse sentido, as projeções desta mobilidade, se projetam constantemente, na formação inicial docente, em Ciências e Biologia e na constituição profissional.

\section{REFERÊNCIAS}

ANTONELli-PONTI, M.; VALENTI, L.; DÍAZ, D. A. C.; PICOLI, R. M. M.; VERSUTI, F. M. Divulgação Científica em Psicobiologia: Educação à Distância como Estratégia para a Promoção da Extensão Universitária. Expressa Extensão, v. 23, n. 3, p. 183-197, set./dez. 2018.

FRANCO, M. C. Cuando nosotros somos el otro. In: LOPES-VELARDE, J. C. (coord.). Teoría y desarrollo de la investigación comparada. México: Plaza y Valdés, 2000. p. 287318.

FREIRE, Paulo. Pedagogia do oprimido. 17ª ed. Rio de Janeiro: Paz e Terra, 1987.

MINEDUC. (2012). Resultados TIMSS 2011. Chile. Estudio Internacional de Tendencias en Matemática y Ciencias. Santiago de Chile: MINEDUC Retirado desde 
Vol. 2, n. 3 - Edição Especial: Ciclos Formativos em Ensino de Ciências.

http://www.agenciaeducacion.cl/wp-content/uploads/2013/02/resultados-timss-18-dic2012.pdf

IZQUIERDO, M. "Enseñar ciencias, una nueva ciencia." Enseñanza de las ciencias sociales: revista de investigación (6): 2007, 125-138.

PORLÁN ARIZA, R. "El maestro como investigador en el aula. Investigar para conocer, conocer para enseñar”. Revista Investigación en la escuela 1. Sevilla, 1987, Diada. QS Latin America Rankings 2019.

Disponível em: https://www.topuniversities.com/university-rankings/latin-americanuniversity-rankings/2019. Acesso em 12 de Julho de 2019.

SANTOS, B. de S. A crítica da razão indolente: contra o desperdício da experiência. São Paulo: Cortez, 2002.

VIGOTSKI, L. S. A construção do pensamento e da linguagem. São Paulo: Martin Fontes, 2001. 